
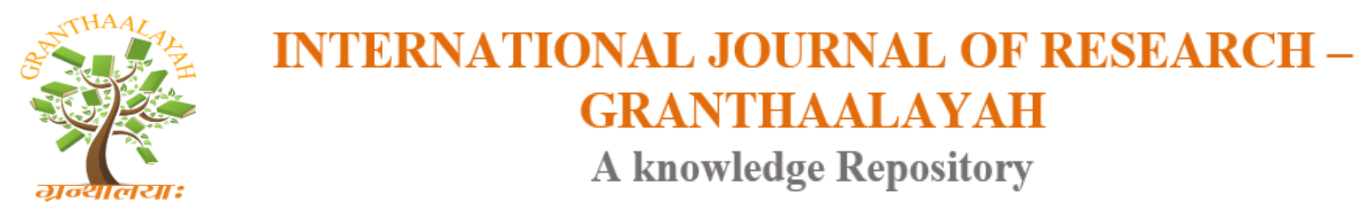

Science

\title{
THE COMPARISON OF CONSERVATIVE TREATMENT AND DOUBLE J STENT INSERTION IN GESTATIONAL HYDRONEPHROSIS
}

\author{
Ŭ̆urkan Erkayıran $^{* 1}$, Bülent Köstü ${ }^{2}$, Alev Özer ${ }^{3}$ \\ *1, 2, 3 Department of Obstetrics and Gynecology, Kahramanmaras Sutcu Imam University, \\ School of Medicine, Kahramanmaraş, Turkey
}

\begin{abstract}
Background: To compare the pregnancy outcomes of patents determined with gestational hydronephrosis and treated with a conservative approach or Double J Stent (DJS) application.

Method: The study included 113 patients diagnosed with gestational hydronephrosis at a university hospital between January 2011 and January 2014. Of the 113 patients, DJS was applied to 51 and a conservative approach was applied to 62 patients. A comparison was made of the pregnancy outcomes in both treatment arms.

Results: No significant difference was determined between the patients in the DJS application group and the patients in the conservative treatment group in respect of age, gravida, parity, gestational week at the time of diagnosis, gestational week at birth, and renal calyx diameter. Although a higher rate of births was determined in the first 24 hours and the first week after placement of DJS in DJS group compared to control group, the difference was not statistically significant. None of the patients in the control group required DJS insertion during the follow-up period.
\end{abstract}

Conclusion: In patients with gestational hydronephrosis, if conservative treatment is first tried, if the patient cannot overcome the symptoms and complications are present, DJS should be inserted.

Keywords: Conservative Treatment; Double J Stent Insertion; Gestational Hydronephrosis.

Cite This Article: Uğurkan Erkayıran, Bülent Köstü, and Alev Özer. (2018). "THE COMPARISON OF CONSERVATIVE TREATMENT AND DOUBLE J STENT INSERTION IN GESTATIONAL HYDRONEPHROSIS." International Journal of Research Granthaalayah, 6(2), 94-100. https://doi.org/10.5281/zenodo.1186225.

\section{Introduction}

In pregnancy, important physiological changes are seen in the urinary system such as an increase in the rate of renal blood flow and glomerular filtration due to increased blood volume and decreased renal vascular resistance [1].

For mechanical and hormonal reasons, dilatation of the ureter and pelvicalyceal system is often seen in pregnancy. Increasing estrogen, progestational hormones and prostaglandin-like agents 
cause dilatation in the urinary system without any obstruction [1]. In the later weeks of pregnancy, as the uterus increases in size, there is physical pressure of the ureter. This process of renal adaptation in pregnancy causes slight pelvicalyceal expansion [2].

Pregnancy-related hydronephrosis has been reported to occur in $80 \%$ of all pregnancies [1]. In many cases, maternal hydronephrosis is defined as a normal finding of pregnancy. Hydronephrosis in pregnancy is generally seen on the right side [3]. Dilatation, which starts in weeks 6-10 of pregnancy, becomes visible with ultrasonography in $90 \%$ of pregnant females in weeks 26-28 of the pregnancy [4].

There is ongoing controversy on the subject of pregnancy-related hydronephrosis and of treatment for patients. In previous studies it has been emphasized that a conservative approach is appropriate first in cases where symptoms have not continued, with no additional complications, with no impairment of renal functions and who are not infectious [5-7]. There are also studies which have recommended more invasive applications such as ureteral catheterization in patients where symptoms have not recovered $[8,9]$.

The aim of this study was to present the pregnancy outcomes of 113 patients who were conservatively treated with the application of DJS for a diagnosis of pregnancy-related hydronephrosis after presenting with complaints of side pain in pregnancy.

\section{Materials and Methods}

A retrospective case control study involving the pregnant patients with the complaint of side pain who presented at the Obstetrics Clinic or at the Urology Clinic of the University Hospital was conducted between January 2011 and January 2014. A total of 137 pregnant patients with symptomatic hydronephrosis were included in the study. Any patients with a history of urinary system disease $(n=11)$ or with systemic disease including diabetes mellitus, hypertension, endocrine disorders $(n=8)$ or those with multiple pregnancies $(n=5)$ were excluded from the study. The data regarding the age of the patient, gestational week at admission, gravida, parity, type of treatment (DJS or conservative treatment), complications which developed in patients where DJS was applied, gestational age at birth, the time from the application of DJS to birth, rate of preterm births, births occurring in the first week after insertion of DJS and the widest diameter of the renal calyx.

Hydronehrosis was diagnosed if the anteroposterior diameter of renal pelvis was $\geq 15 \mathrm{~mm}$ on the renal ultrasonography. Of the total 113 patients included in the study, unilateral DJS was applied to 51 patients and a conservative approach was applied to 62 patients based on the decision of the senior urologist taking care of the patient. In the DJS patient group, the procedure was applied under mask and anaesthesia. Following the procedure, all the patients were followed up in the obstetrics ward for 48 hours. Stents were removed from all the patients by the $12^{\text {th }}$ week postpartum.

The patient group undergoing a conservative approach was admitted to the hospital. In this group, the treatment included daily administration of 2000cc hydration and paracetamol tablets 
given orally 500mg two times a day. Patients who achieved a reduction in symptoms were discharged with planned outpatient follow-up.

In the primary results of this study, a comparison was made of demographic data (age, gestation week, birth week, gravida, parity, renal calyx diameter). As secondary results, comparisons were made of preterm births, the time from application of the DJS to the birth, births in the first 24 hours after treatment and births in the first week after treatment.

Approval for the study was granted by the Local Research Ethics Committee of Kahramanmaraş Sütçü İmam University School of Medicine.

In the statistical analysis of the study data, SPSS 22.0 software (IBM Corporation, Armonk, New York, USA) was used. Conformity to normal distribution of the data was tested with the Shapiro Wilk test and with variable coefficients and for variance homogeneity, the Levene test was used. In the comparison of two independent groups, the Independent Samples t-test was used together with Bootstrap results and the Mann Whitney U-test with the Monte Carlo simulation technique. In the comparison of paired categorical data, the McNemar test with Exact results was used and in the comparison of categorical data, the Fisher Exact test with Exact results. Quantitative data were stated in the tables as mean \pm standard deviation (SD) and median and range (minimummaximum) values. Categorical values were stated as number (n) and percentage (\%). The data were examined at a $95 \%$ confidence interval and a value of $\mathrm{p}<0.05$ was accepted as statistically significant.

\section{Results and Discussions}

The study included a total of 113 patients. Of these, unilateral DJS was applied to 51 as hydronephrosis treatment and conservative treatment was applied to the remaining 62 patients. No statistically significant difference was determined between these two groups in respect of the age, gravida, parity, birth weight, gestational week at the time of diagnosis and at birth. Renal calyx diameter was similar in both groups $(21.7 \mathrm{~mm}$ in DJS group vs $20.6 \mathrm{~mm}$ in conservative treatment group, $\mathrm{p}=0.058$ ). No statistically significant difference was determined between the groups in respect of rate of cesarean section $(\mathrm{p}=0.145)$ (Table 1).

Table 1: Demographic data

\begin{tabular}{|l|l|l|l|}
\hline & $\begin{array}{l}\text { DJS group } \\
(\mathbf{n = 5 1 )}\end{array}$ & $\begin{array}{l}\text { Conservative treatment } \\
(\mathbf{n = 6 2})\end{array}$ & p value \\
\hline Age* $^{*}$ & $26.7 \pm 5.2$ & $27,1 \pm 4.8$ & 0.751 \\
\hline Gravidy* & $2.1 \pm 0.4$ & $2.2 \pm 0.4$ & 0.324 \\
\hline Parity* & $1.1 \pm 0.3$ & $1.2 \pm 0.1$ & 0.115 \\
\hline Gestational age at admission(w)* & $31.3 \pm 2.2$ & $31.5 \pm 1.6$ & 0.575 \\
\hline Gestational age at birth (w)* & $39.2 \pm 2.1$ & $39.4 \pm 1.9$ & 0.288 \\
Birth weight (gram)* & $3221 \pm 340.2$ & $3402 \pm 284.7$ & 0.682 \\
\hline Diameter of renal calyx $(\mathrm{mm})^{*}$ & $21.7 \pm 3.3$ & $20.6 \pm 4.1$ & 0.058 \\
\hline Rate of cesarean section & $17.6 \%$ & \multicolumn{1}{|c|}{$19.4 \%$} & 0.145 \\
\hline
\end{tabular}

w: Weeks, mm: Milimeters

*Values were given as mean \pm standart deviation 
As secondary outcomes of this study, comparisons were made in respect of birth complications of the treatment method applied. None of the patients who had DJS slipped in the stent. Patients who were followed conservatively did not require stents. None of the patients with stents had to remove the stent. The patient groups treated with DJS or conservatively were compared in the first 24 hours after starting treatment and in the first week after giving birth. Although both parameters were determined as higher in the DJS patient group compared to the conservative treatment group, there was no statistically significant difference (Table 2).

Table 2: Comparison of birth rates in both groups

\begin{tabular}{|l|l|l|l|}
\hline & $\begin{array}{l}\text { DJS group } \\
\mathbf{n = 5 1}\end{array}$ & $\begin{array}{l}\text { Conservative treatment group } \\
\mathbf{n = 6 2}\end{array}$ & p value \\
\hline Birth rate within 24 hours after* & $2(3.9 \%)$ & 0 & 0.201 \\
\hline Birth rate within first week* & $5(9.8 \%)$ & $2(3.2 \%)$ & 0.241 \\
\hline
\end{tabular}

$*$ Values were gives as numbers (percentages)

In the current study involving the gestational hydronephrosis cases with side pain, it was determined that the birth weights, the rate of preterm birth and cesarean section were comparable between conservative treatment group and DJS group.

Together with the development of imaging methods, gestational hydronephrosis is often encountered in obstetric clinics with a mild degree of hydronephrosis determined in $90 \%$ of pregnant patients [10].

Hormonal and mechanical factors are the causes most focussed on in the etiology of hydronephrosis developing in pregnancy. Hydronephrosis occurs with stasis in the urinary system associated with the increasing dimension of the uterus in pregnancy. In addition, some researchers have emphasized that progesterone and gonadotropins could have a role in the formation of stasis in pregnancy $[1,5]$. In other studies conducted on the etiology, the relationship has been investigated between fetal weight, fetus presentation, parity and the development of hydronephrosis. It has been suggested that a greater fetal weight, fetal head presentation and nulliparity facilitate hydronephrosis in pregnancy [10-12]. In literature, there are data both supporting and not supporting these findings [13].

The diagnosis and treatment of symptomatic pregnancy-related hydronephrosis has challenges which must be given attention by clinicians. Some researchers have recommended a two-stage method in the management of patients with renal colic [8]. When conservative treatment is not sufficient, the placement of DJS with follow-up until the birth is a simple, effective and safe method [9].

The majority of studies related to gestational hydronephrosis are case reports or are cases of hydronephrosis developing secondary to obstructive pathologies [13-16]. In all of these studies it has been emphasized that the application of DJS is useful in the protection of renal functions and the recovery of symptoms.

In a study by Çeçen et al. [7] comparing conservative and interventional treatments, DJS was applied in cases of isolated symptomatic gestational hydronephrosis and it was reported that a 
significant benefit was observed. In addition, patients with a mild or moderate degree of renal function impairment in the conservative treatment group were hospitalized, hydration was provided and symptoms were brought under control with analgesics. In a similar study by Sadan et al. [17], DJS was applied to patients who developed hydronephrosis in pregnancy and no significant clinical problems were reported. In another study by Tsai et al. [9], a comparison was made of DJS and conservatively treated patients and it was reported that in the patient group treated conservatively, symptoms did not improve in 5 patients and it was necessary to apply DJS. In 4 of these patients, the complaints of side pain continued after the placement of DJS and full recovery was achieved in only one. However, in the study by Çeçen et al [7], surgical treatment was not necessary in any of the conservative treatment group and the complaints recovered with hospitalization, ample hydration and antibiotics. It is recommended by the European Association of Urology that in patients with the complaint of severe renal colic pain associated with gestational hydronephrosis, the first step of the treatment method should be the use of NSAID and dipyrone [24]. In the continuation of treatment, it should be kept in mind that there could be a reduction in amniotic fluid due to long-term use of NSAID and oligohydramnios could develop. Çeçen et al recommend the use of metamizole and paracetamol in conservative treatment and have reported that a more significant improvement in pain score is achieved with this treatment compared to other conservative treatments [7]. In our study, patients who were treated conservatively were admitted to the hospital with $2000 \mathrm{cc}$ hydration daily and oral 500 mg paracetamol twice a day. No additional treatment was needed for any of the patients receiving this treatment.

While no serious complications were reported from the application of DJS to pregnant patients by Çeçen et al [7], in a study by Ringel et al [18], it was reported that the DJS had to be removed before the planned time in $32 \%$ of the patients. When the complications are examined in literature of pregnant patients with symptomatic hydronephrosis, preterm birth rates have been reported as 5-7\% [19], intrauterine growth retardation (IUGR) at 3-7\% [20] and there are also studies reporting that maternal and perinatal outcomes have been negatively affected [10]. In our study we observe that no significant change of preterm birth and intrauterine growth retardation. We were not reported serious complications from the application of DJS.

The most frequent complaints in patients with DJS applied are dysuria, frequent urination, side pain and suprapubic pain [21]. Problems requiring removal or change of the stent, such as urinary system infections, stent migration, the stent being forgotten or obstruction of the stent, must be taken into consideration. Thus potential DJS-related complications can be avoided [22, 23]. In our study, 5 cases of urinary tract infections developed, but none of them required the removal of the DJS. In our study, obstruction and displacement were not observed in any patient's stent.

\section{Conclusions and Recommendations}

In conclusion, based on the findings of the current study are considered, it could be recommended that a conservative approach should be the first-step-treatment in cases with isolated gestational hydronephrosis, followed by DJS placement in patients where there is no improvement in the complaints. The application of DJS if required did not lead to a change in the birthweight and in the rate of preterm birth and cesarean section. 
We would like to thank all our colleagues who helped us in this study and Caroline Walker for English editing.

\section{References}

[1] Nielsen FR, Rasmussen PE. Hydronephrosis during pregnancy: four cases of hydronephrosis causing symptoms during pregnancy. Eur J ObstetGynecolReprod Biol. 1988;27(3):245-8.

[2] Yildirim G, Çetinkaya N, Yencilek F et al. Fizyopatolojik Olarak Gebelik Hidronefrozunun Değerlendirilmesi: Üç Farklı Yaklaşım. ZeynepKamil Tıp Bülteni. 2009: 40:191-5.

[3] Di Salvo DN. Sonographic imaging of maternal complications of pregnancy. J Ultrasound Med. 2003; 22:69-89

[4] Loughlin KR. Management of urologic problems in the pregnant patient. AUA Update Series. 1997; 16:10-15.

[5] Puskar D, Balagović I, Filipović A, et al. Symptomatic physiologic hydronephrosis in pregnancy: incidence, complications and treatment. Eur Urol. 2001; 39:260-3.

[6] Zwergel T, Lindenmeir T, Wullich B. Management of acute hydronephrosis inpregnancybyureteralstenting. EurUrol. 1996;29:292-7.

[7] Çeçen K, Ülker K. The comparison of double J stent insertion and conservative treatment alone in severe pure gestational hydronephrosis: a case controlled clinical study. ScientificWorldJournal. 2014;20; 2014:989173.

[8] Guichard G, Fromajoux C, Cellarier D Et al. Management of renal colic in pregnant women, based on a series of 48 cases. Prog Urol. 2008; 18:29-34.

[9] Tsai YL, Seow KM, Yieh CH et al. Comparative study of conservative and surgical management for symptomatic moderate and severe hydronephrosis in pregnancy: a prospective randomized study. ActaObstetGynecol Scand. 2007; 86:1047-50.

[10] Coban S, Biyik I, Ustunyurt E et al. Is there a relationship between the grade of maternal hydronephrosis and birth weight of the babies? J Matern Fetal Neonatal Med. 2015; 28:1053-6.

[11] RajaeiIsfahani M, Haghighat M. Measurable changes in hydronephrosis during pregnancy induced by positional changes: ultrasonic assessment and its diagnostic implication. Urol J. 2005; 2:97-101.

[12] Faúndes A, Brícola-Filho M, Pinto e Silva JL. Dilatation of the urinary tract during pregnancy: proposal of a curve of maximal caliceal diameter by gestational age. Am J Obstet Gynecol. 1998; 178:1082-6.

[13] Spencer JA, Chahal R, Kelly A Et al. Evaluation ofpainful hydronephrosis in pregnancy: magnetic resonance urographic patterns inphysiological dilatation versus calculousobstruction. J Urol. 2004; 171:256-60.

[14] Sherer DM, Stimphil R, Hellman M Et al. Marked maternal ureteropelvic obstruction mimicking a large ovarian mass at 20 weeks' gestation. J Ultrasound Med. 2005; 24:1309-12.

[15] Song G, Hao H, Wu X Et al. Treatment of renal colic with double-J stent during pregnancy: a report of 25 cases. Zhonghua Yi XueZaZhi. 2011; 91:538-40.

[16] Afzali B, Kingdon E, Holt SG. Treatment of unilateral obstruction reversingheavy and bilateral proteinuria.Nephrol Dial Transplant. 2005; 20:210-2.

[17] Sadan O, Berar M, Sagiv R Et al. Ureteric stent in severe hydronephrosis of pregnancy. Eur J ObstetGynecolReprod Biol. 1994; 56:79-81.

[18] Ringel A, Richter S, Shalev M Et al. Late complications of ureteral stents. EurUrol. 2000; 38:414.

[19] Beck S, Wojdyla D, Say L et al. The worldwide incidence of preterm birth: a systematic review of maternal mortality and morbidity. Bull World Health Organ. 2010; 88:31-8.

[20] Romo A, Carceller R, Tobajas J. Intrauterine growth retardation (IUGR): epidemiology and etiology. PediatrEndocrinol Rev. 2009; 6:332-6. 
[21] Haleblian G, Kijvikai K, de la Rosette J Et al. Ureteral stenting andurinary stone management: a systematicreview. J Urol. 2008; 179:424-30.

[22] Breau RH, Norman RW. Optimal preventionand management of proximal ureteralstent migration and remigration. J Urol. 2001; 166:890-3.

[23] Singh V, Srinivastava A, Kapoor R et al. Can the complicated forgottenindwelling ureteric stents be lethal? IntUrolNephrol. 2005; 37:541-6.

[24] Páez-Borda A, Charnay-Sonnek F, Fonteyne V et al. Guidelines on pain management \& palliative care.European Association of Urology 2014.https://uroweb.org/wp-content/uploads/25-PainManagement_LR.pdf

*Corresponding author.

E-mail address: byugrerk@ hotmail.com 